\title{
Арнаут T.A.
}

\section{Количественное содержание холестерола в организме человека у жителей города Губкинского}

\author{
Arnaut T.A. \\ Formation of healthy lifestyle among the younger generation: \\ the quantitative content of cholesterol in the human \\ body the inhabitants of the city Gubkinsky
}

Количественное определение холестерола является важной практической задачей, поскольку избыток и нарушение обмена данного соединения является причиной очень многих заболеваний человека, занимающих лидирующее место в причинах летальных исходов. Практические и теоретические знания о данном соединении важны для учителя для проведения просвещения среди молодого поколения, формирования у них здорового образа жизни и правильных привычек

Ключевые слова: холестерол, атеросклероз, липопротеины, сердечно-сосудистые заболевания

\section{Арнаут Татьяна Александровна \\ Преподаватель \\ Муравленковский многопрофильный колледж \\ 2. Губкинский, микрорайон 7, 8}

\begin{abstract}
Quantitative determination of cholesterol is an important practical task, since the excess and the metabolism of this compound is the cause of so many human diseases are the leading causes in deaths. Practical and theoretical knowledge about the connection important for the teacher to conduct education among the younger generation, empowering them with a healthy lifestyle and proper habits
\end{abstract}

Key words: cholesterol, lipoproteins, cardiovascular disease, atherosclerosis
Arnaut Tatiana Aleksandrovna
Teacher
Muravlenkovskaya multidisciplinary college
Gubkinskiy, microdistrict 7, 8

Данную статью хотелось бы начать со слов Макклендон Сары: «Здоровье это вопрос номер один. Если у вас слабое здоровье, что толку говорить о хорошей работе, хорошей защите прав, хорошем образовании!»

Таким образом, количественное содержание холестерола в организме человека играет немало важную роль.

Автор статьи исследовал данный показатель - количественное содержание холестерола в организме жителейгорода Губкинского Ямало-Ненецкого автономного округа.

Количественное определение холестерола является важной практической задачей, поскольку избыток и нарушение обмена данного соединения является причиной очень многих заболеваний человека, занимающих лидирующее место в причинах летальных исходов. Практические и теоретические знания о данном 
соединении важны для проведения просвещения среди молодого поколения, формирования у них здорового образа жизни и правильных привычек. Повышенное содержание холестерола в крови - не редкость. По данным медиков, в мире от этого страдает более 147 млн. человек. При этом многие не придают этому факту должного значения, хотя длительное повышение уровня холестерола чревато развитием серьезных заболеваний.Холестерол - органическое жирорастворимое соединение, содержащееся в клетках практически всех живых организмов. Он может поступать в организм с пищей (около 20\% всего количества) или вырабатывается им самостоятельно (около 80\%). Большая часть холестерола синтезируется печенью.Основные функции холестерола: участие в выработке гормонов надпочечников и половых желез, витаминов группы D, а также обеспечение стабильности клеточных мембран и изоляция нервных волокон.В крови холестерол содержится в виде особых комплексных соединений - липопротеинов. Различают несколько их видов.Липопротеины высокой плотности (ЛПВП) не только не приводит к образованию отложений в сосудах, но и препятствуют им, это так называемый «хороший» холестерол. В противоположность им липопротеины низкой плотности (ЛПНП) опасны, так как холестерол из этих соединений способен выпадать в осадок, накапливаясь в кровеносных сосудах. Это так называемый «плохой холестерол». Атеросклероз и связанные с ним сердечно-сосудистые заболевания среди населения промышленно развитых стран занимают первое место в ряду причин смертности от неинфекционных болезней, что диктует необходимость наблюдения и определенияхолестерола в организме человека.В основе гипотезы атерогенеза лежит повреждение клеток сосудистого эндотелия. Достоверно установленной причиной атеросклеротичсеких изменений в сосудах являются нарушения липидного профиля с повышением концентрации общего холестерола в крови. Наиболее агрессивными являются липопротеины низкой плотности (ЛПНП). Окисленные ЛПНП повреждают эндотелий и внутреннюю оболочку сосудов, провоцируя образование атеросклеротических бляшек. Поврежденный эндотелий утрачивает свою способность продуцировать эндогенные вещества, что при определенных обстоятельствах проявляется склонностью к возникновению спазмов, в частности, коронарных артерий. Эпидемиологические исследования, проводившиеся в разных странах, показали, что особенности национального, либо регионального характера питания (количество и качество потребляемых жиров) способны активно влиять на содержание холестерола в крови и на летальность от осложнений сердечно-сосудистых заболеваний. При выборе метода определения холестерола оценивают простоту и скорость выполнения, точность результатов. Компромиссным методом становится тот, который не вносит в деятельность лаборатории проблем и обеспечивает получение надежных результатов [3].

Когда назначается исследование? Не реже одного раз в 5 лет всем взрослым старше 20 лет (обычно он входит в перечень стандартного набора тестов при профилактических осмотрах). Вместе с анализами на ХС ЛПНП, ХС ЛПОНП, ХС ЛПВП, триглицериды и с коэффициентом атерогенности - это так называемая липидограмма. Несколько раз в год, если предписана диета с ограничением животных жиров и/или принимаются лекарства, снижающие уровень холестерола 
(чтобы проверить, достигает ли человек целевого уровня холестерола и, соответственно, снижается ли риск сердечно-сосудистых заболеваний). Если в жизни пациента приутствует один или несколько факторов риска развития сердечно-сосудистых заболеваний:курение, определённый возрастной период (мужчины старше 45 лет, женщины старше 55 лет), повышенное артериального давление (140/90 мм. рт. ст и выше),повышенный уровень холестерола или сердечно-сосудистые заболевания у других членов семьи (инфаркт или инсульт у ближайшего родственника мужского пола моложе 55 лет или женского моложе 65 лет), ишемическая болезнь сердца, перенесённый инфаркт сердечной мышцы или инсульт, сахарный диабет, избыточная масса тела, злоупотребление алкоголем, приём большого количества пищи, содержащей животные жиры, низкая физическая активность.

Концентрация холестерола время от времени может изменяться, это нормально. Единичное измерение не всегда отражает обычный уровень, поэтому иногда может потребоваться пересдать анализ через 1-3 месяца.

Повышают уровень общего холестерола:

- беременность (тест на холестерол следует сдавать, по меньшей мере через 6 недель после родов),

- длительное голодание,

- сдача крови в положении стоя,

- анаболические стероиды, андрогены, кортикостероиды,

- курение,

- приём пищи, содержащей животные жиры.

Снижают уровень общего холестерола:

- сдача крови в положении лёжа,

- аллопуринол, клофибрат, колхицин, противогрибковые препараты, статины, холестирамин, эритромицин, эстрогены,

- интенсивная физическая нагрузка,

- диета с высоким содержанием полиненасыщенных жирных кислот.

\section{Важные замечания}

- Анализ на холестерол необходимо сдавать, когда человек относительно здоров. После острого заболевания, инфаркта, хирургической операции перед измерением холестерола следует подождать как минимум 6 недель.

- В США холестерол измеряется в миллиграммах на децилитр, в России и в Европе - в миллимолях на литр. Пересчёт осуществляется по формуле: ХC $(\mathrm{мг} /$ дл) $=$ ХС (ммоль/л) × 38,5 или ХC (ммоль/л) = ХC (мг/дл) х 0,0259.

В нашей работе использовался метод Илька для определения общего холестерола в крови, относящийся к колориметрическим способам. Остановимся на принципе метода. В сильнокислой безводной среде холестерол взаимодействуют со смесью серной, уксусной кислот и уксусного ангидрида. В ходе реакции холестерол последовательно окисляется. При этом каждая стадия реакции сопровождается образованием производных холетсерола, которые имеют на одну двойную связь больше. В результате конечного окисления получается окрашенное соединение, растворенное в серной кислоте, концентрация которого определяется фотометрически. Из-за неустойчивости окраски соединения время фотометрирования должно быть точно выдержано.Нормальный уровень 
общего холестерола в крови по методу Илька 4,65-6,46 ммоль/л (180-250 мл/децилитр) [1, с.38].

Нами было проанализировано порядка 420 проб в возрасте от 13 лет и выше. Всего в серии эксперимента $75,2 \%$ реципиентов содержат нормальный уровень холестерола. Пониженное содержание холестерола у $4,7 \%$ женщин и 12,4 \% мужчин. Повышенное содержание холестерола у 19,5\% женщин и $13 \%$ мужчин.

Полученные данные свидетельствуют о высоком содержании холестерола у женщин и о пониженном содержании холестерола у мужчин города Губкинский.

Обладатели низкого уровня холестерола в крови находятся в группе риска - таким людям угрожают геморрагический инсульт мозга и депрессии. Дефицит холестерола вызывает ожирение (жиры не перевариваются так, как надо). Причинами, вызывающими пониженный холестерол в крови, являются: хроническая сердечная недостаточность; анемия, при которой гемоглобин в крови снижается; инфекционные заболевания; излишняя выработка гормонов щитовидной железы [2, с.17].

Повышенное содержание холестерола может быть по многим причинам. Рассмотрим самые распространенные. Неправильное питание.Многие продукты питания содержат холестерол. В первую очередь продукты животного производства (сыр, молоко, яйца). Сильное влияние оказывают продукты, содержащие насыщенные жиры (колбасные изделия, красное мясо, а также кондитерские изделия, которые содержат большое количество крема и сливок). Вес, образ жизни. Кроме питания влияние на высокий уровень холестерола оказывает образ жизни человека и его вес. Люди с избыточным весом, которые ведут малоподвижный образ жизни (то есть большую часть времени суток проводят в сидячем или лежачем положении) имеют более высокий уровень холестерола.Курение, алкоголизм. Чрезмерное употребление алкогольных напитков и курение оказывают большое влияние на повышенный уровень холестерола. Это самые распространенные причины повышенного уровня в России.Болезни. Среди наиболее распространенных - заболевания почек, печени, щитовидной железы. Высокое кровяное давление и диабет [3].

Все вышеперечисленные факторы повышенного уровня холестерола поддаются влиянию со стороны самого человека. Здоровый образ жизни, правильное питание, своевременное обращение к врачу, который правильно назначит курс лечения, поможет держать в норме уровень холестерола [3].

\section{Список используемых источников:}

1. Актуальные проблемы химического и естественнонаучного образования. Тобольск: ТГСПА им. Д.И. Менделеева, 2013. 149 с.

2. Буханов Ю. Холестерин и атеросклероз // Спортивная жизнь России. 2001. С. 26-28.

3. Все про холестерол: норма в крови, как снизить вес, советы и рекомендации. URL: www.fitfan.ru

(C) 2016, Арнаут T.A.

Количественное содержание холестерола в организме человека у жителей города Губкинского
(C) 2016, Arnaut T.A.

Formation of healthy lifestyle among the younger generation: the quantitative content of cholesterol in the human body the inhabitants of the city Gubkinsky 